\title{
Frutos e sementes em Schultesia Mart. e Xestaea Griseb. (Gentianaceae) ${ }^{1}$
}

\author{
Elsie Franklin Guimarães ${ }^{2,3}$, Mariana Machado Saavedra e Cecília Gonçalves Costa ${ }^{2}$
}

Recebido em 27/01/2006. Aceito em 28/09/2006

\begin{abstract}
RESUMO - (Frutos e sementes em Schultesia Mart. e Xestaea Griseb. (Gentianaceae)). Este trabalho tem por objetivo a descrição dos frutos e sementes das espécies dos gêneros Schultesia Mart., com 21 táxons, e Xestaea Griseb., monotípico. A morfologia da testa das sementes é apresentada com o auxílio da microscopia eletrônica de varredura (MEV). Buscaram-se caracteres que auxiliassem a separação dos gêneros e espécies, contribuindo para a discussão das delimitações entre os mesmos. Alguns destes caracteres mostraram valor taxonômico. Os frutos são cápsulas septicidas, bivalvares, com cálice persistente e numerosas sementes em ambos os gêneros. A forma e a consistência dos funículos, assim como a superfície da testa das sementes, permitiram o estabelecimento de grupos, auxiliando na identificação das espécies. O padrão estriado das paredes periclinais das sementes de Xestaea é distinto daqueles assinalados para Schultesia, corroborando com estudos morfológicos e moleculares que propiciaram o recente restabelecimento de Xestaea. Neste trabalho constam descrições e ilustrações.
\end{abstract}

Palavras-chave: Schultesia, Xestaea, frutos, sementes, Gentianaceae

\begin{abstract}
Fruits and seeds of Schultesia Mart. and Xestaea Griseb. (Gentianaceae)). This work describes the fruits and seeds of species of the genus Schultesia Mart. with 21 taxons and the monotypic Xestaea Griseb. Seed coat morphology was investigated with scanning electron microscopy (SEM). We searched for characters that would help to separate the genera and species, and these contributed to the discussion on taxa delimitation. Some of the characters have taxonomic value. The fruits of both genera are septicidal bivalvar capsules with a persistent calyx and numerous seeds. Form and consistency of the funiculus, as well as the seed coat surface, allowed us to establish groups, thus helping in species identification. The grooved pattern of the periclinal walls of Xestaea seeds is distinct from that of Schultesia seeds, which agrees with morphological and molecular studies that led to the recent reestablishment of Xestaea. Descriptions and illustrations complete this work.
\end{abstract}

Key words: Schultesia, Xestaea, fruits, seeds, Gentianaceae

\section{Introdução}

Schultesia foi descrito por Martius (1827) com três espécies, sobre as quais fez detalhadas diagnoses acompanhadas de ilustrações. Outros autores dedicaram-se também ao estudo das Gentianaceae (Grisebach 1836; 1845; 1849; Miquel 1847; Progel 1865; Bentham \& Hooker 1876; Gilg 1895), ora descrevendo espécies, ora estabelecendo sistemas de classificação.

O gênero Xestaea foi descrito por Grisebach (1849) com uma única espécie, e posteriormente incluído em Schultesia por Gilg (1895) com base na morfologia do cálice, dos estames e placentas, mantendo-o na Seção Xestaea junto a três outras espécies de Schultesia. Struwe et al. (2002), com base em seus estudos de biologia molecular, na morfologia de numerosos gêneros das Gentianaceae, e nos resultados palinológicos obtidos por Elias \& Robyns (1975) e Nilsson (2002), restabeleceram Xestaea, inserindo-o junto a Schultesia na subtribo Coutoubeinae.

Schultesia está constituído por 21 táxons com distribuição pantropical e cujo centro de diversidade está situado na América do Sul, especialmente no Brasil, onde é representado por 20 táxons, enquanto Xestaea ocorre na América Central e no norte da América do Sul.

De um modo geral, o estudo morfológico das cápsulas, feito pelos autores do século XIX é sucinto em relação às suas descrições genéricas.

Martius (1827) descreveu o fruto de Schultesia como cápsula polisperma, oblonga, lanceolada, bivalvar, rostrada; corola e cálice persistentes. Grisebach (1845)

\footnotetext{
1 Parte da tese de doutorado da primeira Autora

2 Instituto de Pesquisas Jardim Botânico do Rio de Janeiro, Rua Pacheco Leão 915, 22460-030 Rio de Janeiro, RJ, Brasil

3 Autor para correspondência: eguimar@jbrj.gov.br
} 
acrescentou que se tratava de uma cápsula septicida, subunilocular, com placentas distintas para o interior e sementes imersas nas placentas. Progel (1865), por sua vez, mencionou que o fruto está incluso no cálice aumentado. Bentham \& Hooker (1876) citaram que as valvas dispõem de margens placentíferas involutas, pouco ou muito dirigidas para dentro e Gilg (1895) em descrição posterior, concordou com estes autores.

Grisebach (1849) descreveu o fruto de Xestaea como uma cápsula bivalvar, septicida, de margens introflexas e placentas inseridas nas margens, com funículos distintos. Citou, em sua única espécie, que a cápsula é oblongo-cilíndrica e as sementes diminutas e levemente rugosas. A maioria dos autores informou que as cápsulas dos gêneros em pauta apresentam sementes diminutas e numerosas, com testa foveolada (Aublet 1775; Endlicher 1838; Bentham \& Hooker 1876; Baillon 1889; Lemée 1934; Standley \& Williams 1969; Sauget \& Liogier 1957; Elias \& Robyns 1975). Apenas Martius (1827) e Progel (1865) mencionaram a forma e textura das mesmas bem como o aspecto da testa.

Recentemente, Bouman et al. (2002) mostraram a diversidade das sementes em diversos gêneros de Gentianaceae. Dentre eles, descreveram as sementes para os gêneros Schultesia e Xestaea tratando de três espécies de Schultesia e de X. lisianthoides. Os autores afirmaram ainda que as sementes de Xestaea assemelham-se a algumas das espécies de Schultesia.

Este trabalho, que faz parte de revisão taxonômica (Guimarães, dados não publicados), tem por objetivo a descrição dos frutos e sementes das espécies dos gêneros Schultesia e Xestaea, visando contribuir para a discussão das delimitações entre os mesmos.

\section{Material e métodos}

Para a análise morfológica dos frutos e sementes utilizou-se material herborizado proveniente dos herbários: ALCB, C, CEPEC, CH, ESA, HBR, HRB, HUFU, MAC, MBM, MG, NY, PACA, R, RB, SP, SPF, U, UB, UC, UEC, US (siglas conforme Holmgren et al. 1990).

Foram selecionadas cápsulas abertas ou em início de abertura, com o objetivo de trabalhar com material cujo grau de maturação fosse aproximadamente igual. Com o objetivo de observar a deiscência das cápsulas, foram coletados exemplares contendo frutos, trazidos ao laboratório e acompanhado o término da maturação, depositados no RB.
O material foi analisado e mensurado em microscópio estereoscópico binocular Zeiss Stemi SV-6, fazendo-se desenhos com auxílio de câmara clara, sendo as respectivas escalas obtidas com a mesma combinação óptica.

As sementes retiradas do material herborizado foram fixadas, sem tratamento prévio, com fita tape dupla face em lamínulas, e levadas à câmara de vácuo do microscópio eletrônico Leo 435VP. A análise foi elaborada no programa LEO v03.01 e as imagens computadorizadas obtidas nas magnitudes $551 \mathrm{x}$ e 1500x, respectivamente para o aspecto geral das sementes e para os detalhes.

As sementes foram analisadas tomando por base os trabalhos de Barthlott (1981), Carvalho et al. (1999), Cobb \& Maas (1983), Grothe \& Maas (1984) e Murley (1951 apud Stearn 1995).

Os materiais examinados foram os seguintes: Schultesia angustifolia Griseb.: W.G. Eiten \& L.T. Eiten 4409 (SP), A. Netto 47 (R); Schultesia aptera Cham. var. aptera: G.M. Araújo 905 (HUFU), J.M. Pires et al. 9158 (RB); Schultesia aptera var. multidentata E.F. Guim. \& Fontella: E.F. Guimarães G-1701, G-1702 (RB); Schultesia australis Griseb.: O. Camargo 66 (PACA); Schultesia bahiensis E.F.Guim. \& Fontella: G.C.P. Pinto 391 (HRB); M.L. Guedes 1119 (ALCB), H.P. Bautista \& S.J. Filho 1123 (HBR); Schultesia benthamiana Klotzsch ex Griseb.: Ph. Luetzelburg 1489 (RB); Schultesia brachyptera Cham.: A. Ducke 10643 (MG); Schultesia crenuliflora Mart.: R.M. Harley 15679 (RB); Schultesia doniana Progel: G.L. Esteves et al. 1770 (SPF), R. Rocha 370 (MAC), M. Fonseca s.n. (ESA); Schultesia gracilis Mart.: A.C. Brade \& A. Barbosa 17687 (RB), E.F. Guimarães M-1693 (RB); Schultesia guianensis (Aubl.) Malme var. guianensis: Cavalo et al. 891 (HRB), T.S. Santos 3166 \& A.M. Silva 119 (CEPEC); Schultesia guianensis var. latifolia (Mart. ex Progel) E.F.Guim. \& Fontella: E.F. Guimarães RJ-1652, RJ-1653, RJ1654, RJ-1655, RJ-1656 (RB), E.F. Guimarães \& J.R. Miguel RJ-1657, RJ-1658, RJ-1659 (RB); Schultesia heterophylla Miq.: J.M. Pinheiro Sobrinho s.n. (BHCB), A. Macedo 34 (SP); Schultesia mexicana S.Watson: C.G. Pringle 2598 (US); Schultesia minensis E.F.Guim. \& Fontella: H.S. Irwin et al. 27561 (NY), A.B. Joly et al. 834 (UEC); Schultesia pachyphylla Griseb.: G. Martinelli 5475 (RB), G. Hatschbach \& R. Kummrow 47936 (C); Schultesia piresiana E.F.Guim. \& Fontella: J.M. Pires 
58155 (U); Schultesia pohliana Progel: H.S. Irwin et al. 17070 (UB), N. Saddi 9059 (CH), J.S. de Assis 402 (ALCB), G. Hatschbach et al. 62250 (MBM); Schultesia subcrenata Klotzsch ex Griseb.: R. Spruce 1028 (RB); Schultesia sucreana E.F.Guim. \& Fontella: E.F. Guimarães \& G.M. Barroso 163 (RB); Xestaea lisianthoides Griseb.: F.W. Pennell 4064 (US), W.H. Lewis et al. 5206 (UC).

Devido à falta de cápsulas desenvolvidas no material examinado de $S$. irwiniana E.F. Guim. \& Fontella, não foi possível a realização das análises morfológicas dos frutos e sementes desta espécie.

\section{Resultados}

\section{Schultesia angustifolia Griseb.}

Fig. 44-45

Cápsula lanceolada, base obtusa ou aguda, ápice agudo, ereto, coriácea, 9-10,2 mm compr., 2,2-2,6 mm larg.; valva com abertura interna retilínea, $1 \mathrm{~mm}$ larg.; funículos curtos, membranáceos, ca. $0,1 \mathrm{~mm}$ compr.; cálice persistente, 10-11 mm larg. Semente ovóide, cônica ou esférica; superfície da testa foveolada, fóveas irregulares; relevo formado pela projeção das paredes anticlinais acentuadamente sinuosas que constituem muri, presença de micropapilas; parede periclinal com padrão liso.

\section{Schultesia aptera Cham. var. aptera}

Fig. 23, 42-43

Cápsula lanceolada, base obtusa, ápice agudo, ereto ou curvo, coriácea, 12-13 mm compr., 2-2,2 mm larg.; valva com abertura interna retilínea, 0,6-0,7 mm larg.; funículos curtos, espessos, 0,2-0,3 mm compr.; cálice persistente, 4,5-5 mm larg. Semente ovóide; superfície da testa foveolada, fóveas irregulares; relevo formado pela projeção das paredes anticlinais retilíneas que constituem muri, presença de micropapilas; parede periclinal com padrão reticulado-foveado de paredes espessas.

Schultesia aptera var. multidentata E.F. Guim. \& Fontella

Cápsula elíptica, base obtusa, ápice agudo, levemente curvo, coriácea, 8,3-8,5 mm compr., 1,8-2 mm larg., valva com abertura interna retilínea, 0,6-0,7 mm larg.; funículos curtos, membranáceos, 0,2-0,4 mm compr.; cálice persistente, 4,5-5 mm larg. Semente esférica ou ovóide; superfície da testa foveolada, fóveas irregulares; relevo formado pela projeção das paredes anticlinais retilíneas ou curvas que constituem muri, presença de micropapilas; parede periclinal com padrão reticulado-foveado de paredes espessas.

\section{Schultesia australis Griseb.}

Fig. 11, 14, 36-37

Cápsula lanceolada, base obtusa, ápice agudo, ereto, coriácea, 11-11,5 mm compr., 2,5-3 mm larg.; valva com abertura interna maior na parte superior, base 0,8 mm larg., ápice 1,8 mm larg.; funículo curto, membranáceo, 0,1-0,4 mm compr.; cálice persistente, 8,5-9 mm larg. Semente piramidal ou poligonal; superfície da testa foveolada, fóveas irregulares; relevo formado pela projeção das paredes anticlinais sinuosas ou retas que constituem muri, presença de micropapilas; parede periclinal com padrão reticulado, com células de perfil poligonal de paredes delgadas.

\section{Schultesia bahiensis E.F. Guim. \& Fontella}

Fig. 27

Cápsula elíptica, ovado-lanceolado, base obtusa, ápice agudo, levemente curvo, coriácea, 17,7-18,4 mm compr., 4,8-5,4 mm larg.; valva com abertura interna levemente maior na parte superior, base 0,5-1 mm larg., ápice 1-1,5 mm larg.; funículo longo, espesso, 0,4-1 mm compr.; cálice persistente, 7,5-11 mm larg. Semente ovóide, piramidal, cônica; superfície da testa foveolada, fóveas irregulares; relevo formado pela projeção das paredes anticlinais retilíneas ou curvas que constituem muri, presença de micropapilas; parede periclinal com padrão reticulado, com células de perfil poligonal de paredes espessas.

\section{Schultesia benthamiana Klotzsch ex Griseb.}

Fig. 24, 46-47

Cápsula oblongo-lanceolada, lanceolada, base aguda ou obtusa, ápice agudo, ereto, coriácea, 8-10 mm compr., 2,4-2,5 mm larg.; valva com abertura retilínea, 0,5 mm larg.; funículo curto, espesso, 0,2-0,4 mm compr.; cálice persistente, 4,7-4,8 mm larg. Semente esférica, ovóide, ou piramidal; superfície da testa foveolada, fóveas irregulares; relevo formado pela projeção das paredes anticlinais com sinuosidade acentuada em V que constituem muri; presença de micropapilas; parede periclinal com padrão foveolado de paredes espessas.

\section{Schultesia brachyptera Cham.}

Fig. 16, 20, 34-35 
Cápsula elíptica, ovada, base obtusa, ápice agudo, curvo, coriácea, 13-15 mm compr., 6-6,2 mm larg.; valva com abertura interna maior na parte superior, base 1,8 mm larg., ápice 4,8 mm larg.; funículo longo, membranáceo, 0,4-0,6 mm compr.; cálice persistente, 5,8-6,6 mm larg. Semente ovóide ou piramidal; superfície da testa foveolada, fóveas irregulares; relevo formado pela projeção das paredes anticlinais retas ou curvas que constituem muri; presença de micropapilas; parede periclinal com padrão reticulado, com células de perfil poligonal de paredes delgadas, geralmente com micropapilas nos vértices.

\section{Schultesia crenuliflora Mart.}

Fig. 12, 28

Cápsula oblongo-lanceolada, base obtusa, ápice agudo, levemente curvo, coriácea, 14,3-16,2 mm compr., 4-4,5 mm larg.; valva com abertura interna retilínea, ca. 0,6 mm; funículo longo, espesso, 0,4-0,8 mm compr.; cálice persistente, 11-13 mm larg. Semente esférica, piramidal, poligonal; superfície da testa foveolada, fóveas irregulares; relevo formado pela projeção das paredes anticlinais sinuosas que constituem muri; presença de micropapilas; parede periclinal com padrão reticulado, com células de perfil poligonal de paredes espessas.

\section{Schultesia doniana Progel}

Fig. 19, 22

Cápsula elíptica ou lanceolada, base obtusa, ápice agudo, levemente curvo, coriácea, 7,5-9 mm compr., 1,9-2 mm larg.; valva com abertura interna maior na parte superior, base ca. 0,7 mm larg., ápice ca. 1,3 mm larg.; funículo curto, membranáceo, 0,2-0,4 mm compr.; cálice persistente, 4,5-6,5 mm larg. Semente esférica, cônica, piramidal ou tetraédrica; superfície da testa foveolada, fóveas irregulares; relevo formado pela projeção das paredes anticlinais acentuadamente sinuosas que constituem muri; presença de micropapilas; parede periclinal com padrão reticuladofoveado de paredes espessas.

\section{Schultesia gracilis Mart.}

Fig. 15

Cápsula elíptica, base truncada, obtusa, ápice agudo, curvo , coriácea, 8-10 mm compr., 3,9-4 mm larg.; valva com abertura interna maior na parte superior, base ca. 1,9 mm larg., ápice ca. 2,6 mm larg.; funículo curto, membranáceo, 0,1-0,2 mm compr.; cálice persistente, 4,3-12 mm larg. Semente esférica, ovóide ou cônica; superfície da testa foveolada, fóveas irregulares; relevo formado pela projeção das paredes anticlinais retilíneas ou levemente curvas que constituem muri; presença de micropapilas; parede periclinal com padrão reticulado, com células de perfil poligonal de paredes delgadas.

\section{Schultesia guianensis (Aubl.) Malme var. guianensis} Fig. 17

Cápsula elíptica, lanceolada, base arredondada, obtusa, ápice agudo, ereto, coriácea, 9-12 mm compr., 2,4-2,6 mm larg.; valva com abertura interna maior na parte superior, base 0,5-1 mm larg., ápice 2,3-3,2 mm larg.; funículo longo, membranáceo, 0,4-0,6 mm compr.; cálice persistente, 5-10 mm larg. Semente ovóide, piramidal, esférica, tetraédrica ou cônica; superfície da testa foveolada, fóveas irregulares; relevo formado pela projeção das paredes anticlinais sinuosas que constituem muri; presença de micropapilas; parede periclinal com padrão reticulado, com células de perfil poligonal de paredes espessas.

Schultesia guianensis var. latifolia (Mart. ex Progel) E.F. Guim. \& Fontella

Fig. 1-6, 8, 18, 21, 38-39

Cápsula oblonga, elíptica, base obtusa, ápice agudo, ereto, coriácea, 7,8-8 mm compr., 2,3-2,5 mm larg., valva com abertura interna maior na parte superior, base $1,3 \mathrm{~mm}$, ápice $2,5 \mathrm{~mm}$; funículo curto, membranáceo, 0,2-0,4mm compr.; cálice persistente, 5-10 mm larg. Semente ovóide, piramidal, esférica, tetraédrica ou cônica; superfície da testa foveolada, fóveas irregulares; relevo formado pela projeção das paredes anticlinais sinuosas que constituem muri; presença de micropapilas; parede periclinal com padrão reticulado, com células de perfil poligonal de paredes espessas.

\section{Schultesia heterophylla Miq.}

Fig. 13

Cápsula oblonga, lanceolada, base obtusa, ápice agudo, ereto, coriácea, 10-20 mm compr., 2,5-3 mm larg.; valva com abertura interna alargando-se nas extremidades, base e ápice ca. 1,4 mm larg.; funículo longo, membranáceo, 0,4-0,5 mm compr.; cálice persistente, 8,5-11 mm larg. Semente cônica, ovóide ou piramidal; superfície da testa foveolada, fóveas irregulares; relevo formado pela projeção das paredes anticlinais retilíneas, raro sinuosas, que constituem muri; presença de micropapilas; parede periclinal com padrão 
reticulado, com células de perfil poligonal de paredes delgadas, geralmente com micropapilas nos vértices.

\section{Schultesia mexicana S.Watson}

Cápsula elíptica, base aguda, ápice agudo, ereto, coriácea, 6,3-6,5 mm compr., 2,6-2,7 mm larg.; valva com abertura interna maior na parte superior, base ca. $1 \mathrm{~mm}$ larg., ápice 1,3-1,5 mm larg.; funículo curto, membranáceo, ca. 0,2 mm compr.; cálice persistente, 5-5,3 mm larg. Semente ovóide ou piramidal; superfície da testa ruminado-foveada, fóveas irregulares; relevo formado pela projeção das paredes anticlinais sinuosas que constituem muri; ausência de micropapilas; parede periclinal de padrão liso.

Schultesia minensis E.F. Guim. \& Fontella.

Fig. 25

Cápsula elíptica, base aguda, ápice agudo, ereto, coriácea, 9-10 mm compr., 2,8-3 mm larg.; valva com abertura interna maior na parte superior, base 1-1,1 mm larg., ápice 2,1-2,2 mm larg.; funículo curto, espesso, 0,2-0,3 mm compr.; cálice persistente, 12-13 mm larg. Semente esférica, ovóide ou cônica; superfície da testa foveolada, fóveas irregulares; relevo formado pela projeção das paredes anticlinais retilíneas ou curvas que constituem muri; presença de micropapilas; parede periclinal com padrão reticulado-foveado de paredes espessas.

\section{Schultesia pachyphylla Griseb.}

Fig. 7, 9-10, 29-31

Cápsula elíptica, base obtusa, ápice atenuado, curvo, coriácea, 10-11 mm compr., 3-3,2 mm larg.; valva com abertura retilínea, base e ápice ca. $0,3 \mathrm{~mm}$ larg.; funículos longos, espessos, 0,4-0,6 mm compr.; cálice persistente, 10-10,5 mm larg. Semente esférica; superfície da testa ruminada; relevo formado pela projeção das paredes anticlinais sinuosas que constituem muri; ausência de micropapilas; parede periclinal com padrão liso.

\section{Schultesia piresiana E.F. Guim. \& Fontella}

Fig. 40-41

Cápsula elíptica, ovada, base obtusa, ápice agudo, ereto, coriácea, 9-12 mm compr., 3-3,4 mm larg.; valva com abertura interna maior na parte superior, base 0,3-0,4 mm larg., ápice 1-1,2 mm larg.; funículo curto, membranáceo, 0,1-0,3 mm compr.; cálice persistente, 10-13 mm larg. Semente esférica, piramidal ou tetraédrica; superfície da testa foveolada, fóveas irregulares; relevo formado pela projeção das paredes anticlinais sinuosas que constituem muri; presença de micropapilas; parede periclinal com padrão reticulado, com células de perfil poligonal de paredes espessas.

\section{Schultesia pohliana Progel}

Cápsula oblongo-elíptica, lanceolada, base obtusa, ápice agudo, levemente curvo, coriácea, 7-8 mm compr., 3-3,5 mm larg.; valva com abertura interna retilínea, ápice e base ca. 0,5 mm larg.; funículo curto, membranáceo, 0,1-0,2 mm compr.; cálice persistente, 4,1-4,2 mm larg. Semente ovóide ou piramidal; superfície da testa ruminada; relevo formado pela projeção das paredes anticlinais sinuosas que constituem muri; presença de micropapilas; parede periclinal com padrão liso.

\section{Schultesia subcrenata Klotzsch ex Griseb.}

Fig. 26

Cápsula elíptica, base aguda, obtusa, ápice agudo, ereto, coriácea, 4,8-5 mm compr., 1,4-1,5 mm larg.; valva com abertura interna retilínea, ca. $0,4 \mathrm{~mm}$ larg.; funículo curto, espesso, ca. $0,1 \mathrm{~mm}$ compr.; cálice persistente, 4,5-4,8 mm larg. Semente ovóide; superfície da testa foveolada, fóveas irregulares; relevo formado pela projeção das paredes anticlinais sinuosas que constituem muri; presença de micropapilas; parede periclinal com padrão liso.

Schultesia sucreana E.F. Guim. \& Fontella.

Cápsula lanceolada, base aguda, ápice agudo, ereto, coriácea, 5,5-5,7 mm compr., 1-1,2 mm larg.; valva com abertura interna retilínea, ca. 0,5 mm larg.; funículo curto, espesso, 0,2-0,4 mm compr.; cálice persistente, 1-2 mm larg. Semente ovóide ou piramidal; superfície da testa foveolada, fóveas irregulares; relevo formado pela projeção das paredes anticlinais sinuosas que constituem muri; presença de micropapilas; parede periclinal de padrão reticulado, com células de perfil poligonal de paredes delgadas.

\section{Xestaea lisianthoides Griseb.}

Fig. 32-33

Cápsula lanceolada, base obtusa, ápice agudo, ereto, papirácea, 9-10 mm compr., 2,4-2,7 mm larg.; valva com abertura interna retilínea, ca. 0,5 mm larg.; funículo curto, espesso, ca. 0,2 mm compr.; cálice persistente, 4-4,5 mm larg. Semente tetraédrica, ovóide ou piramidal; superfície da testa foveolada, fóveas irregulares; relevo formado pela projeção das paredes 

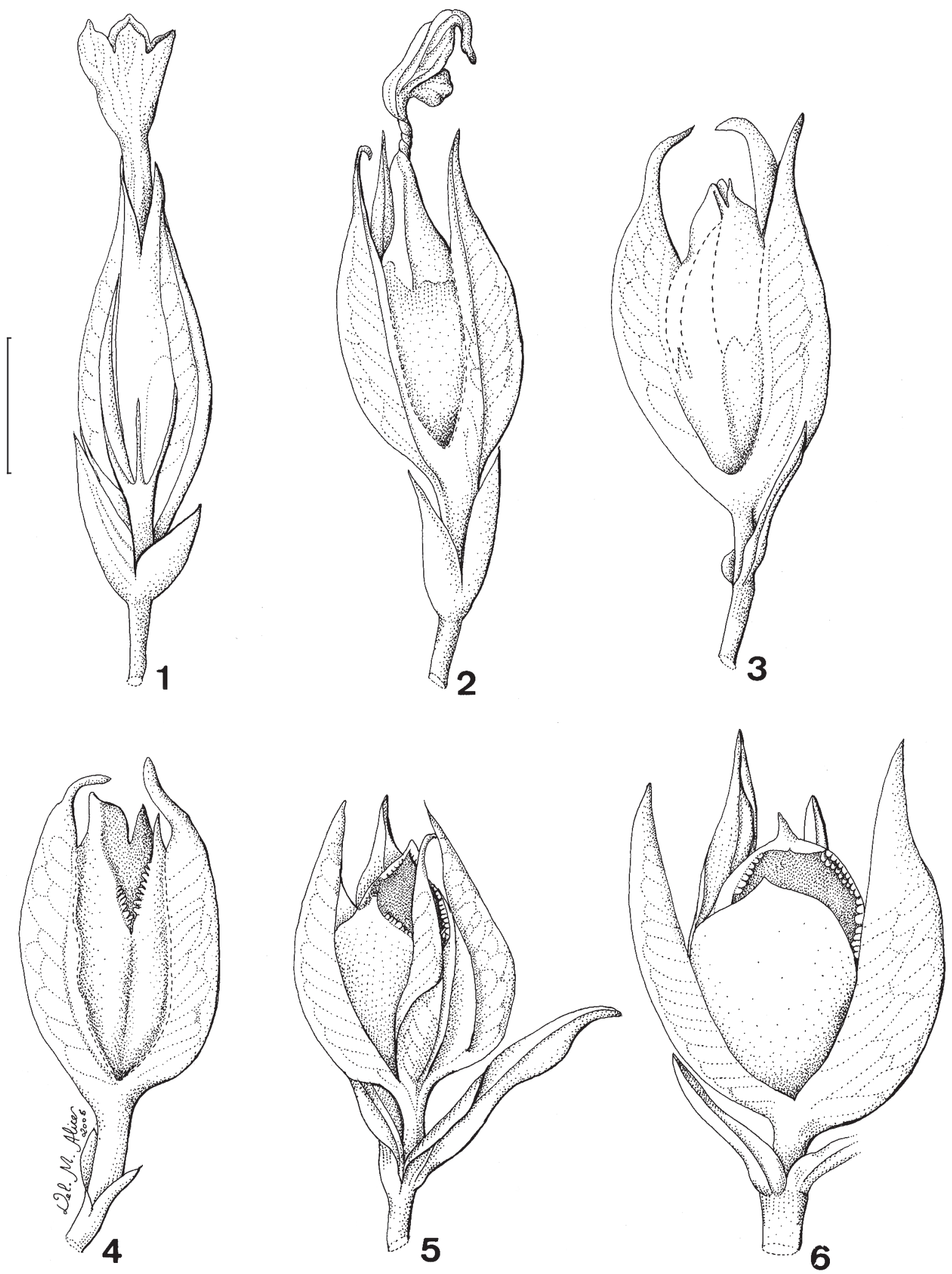

Figuras 1-6. Schultesia guianensis var. latifolia. 1. Flor em início de desenvolvimento da cápsula. 2. Cápsula desenvolvida com a corola marcescente torcida. 3. Cápsula em início da abertura com cálice persistente. 4. Cápsula aberta mostrando a deiscência no septo. 5-6 Cápsulas abertas mostrando a separação dos carpelos, o cálice persistente e vestígios do estilete. (Escala: 1-6 = 5 mm) $(\mathrm{Guimarães}$ RJ-1652, RJ-1653, RJ-1654). 

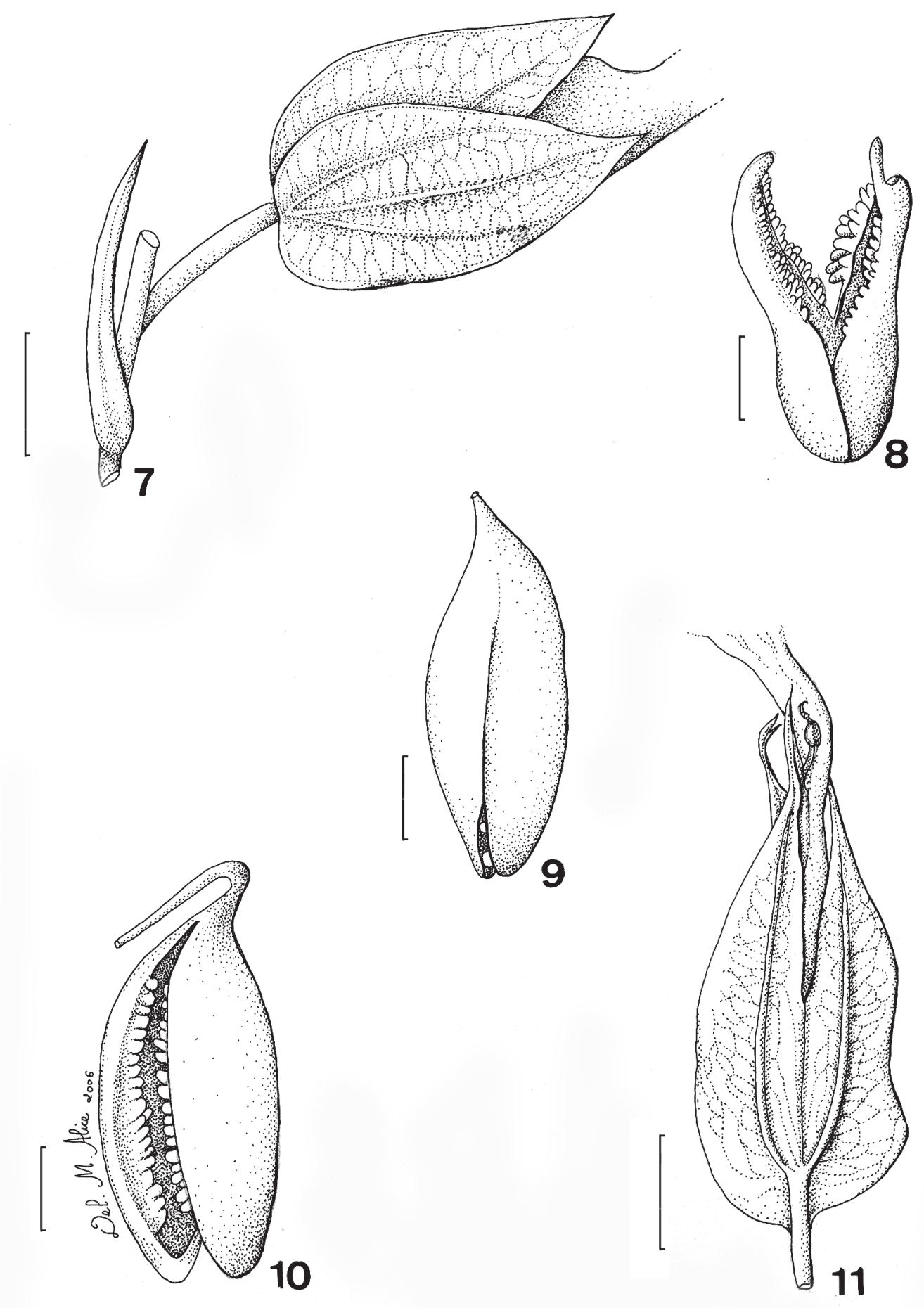

Figuras 7-11. Cápsulas de Schultesia. 7. S. pachyphylla (Martinelli 5475), mostrando cálice íntegro. 8. S. guianensis var. latifolia (Guimarães \& Miguel RJ-1658), mostrando a deiscência do ápice para a base, vestígio do estilete e funículos aparentes. 9-10. S. pachyphylla (Hatschbach \& Kummrow 47936; Martinelli 5475). 9. Início de deiscência na base. 10. Deiscência da cápsula da base para o ápice, com vestígio do estilete no ápice e funículos aparentes. 11. S. australis (Camargo 66), cálice persistente e vestígios da corola marcescente e de estame. (Escalas: $8-10=2 \mathrm{~mm} ; 7,11=5 \mathrm{~mm}$ ). 

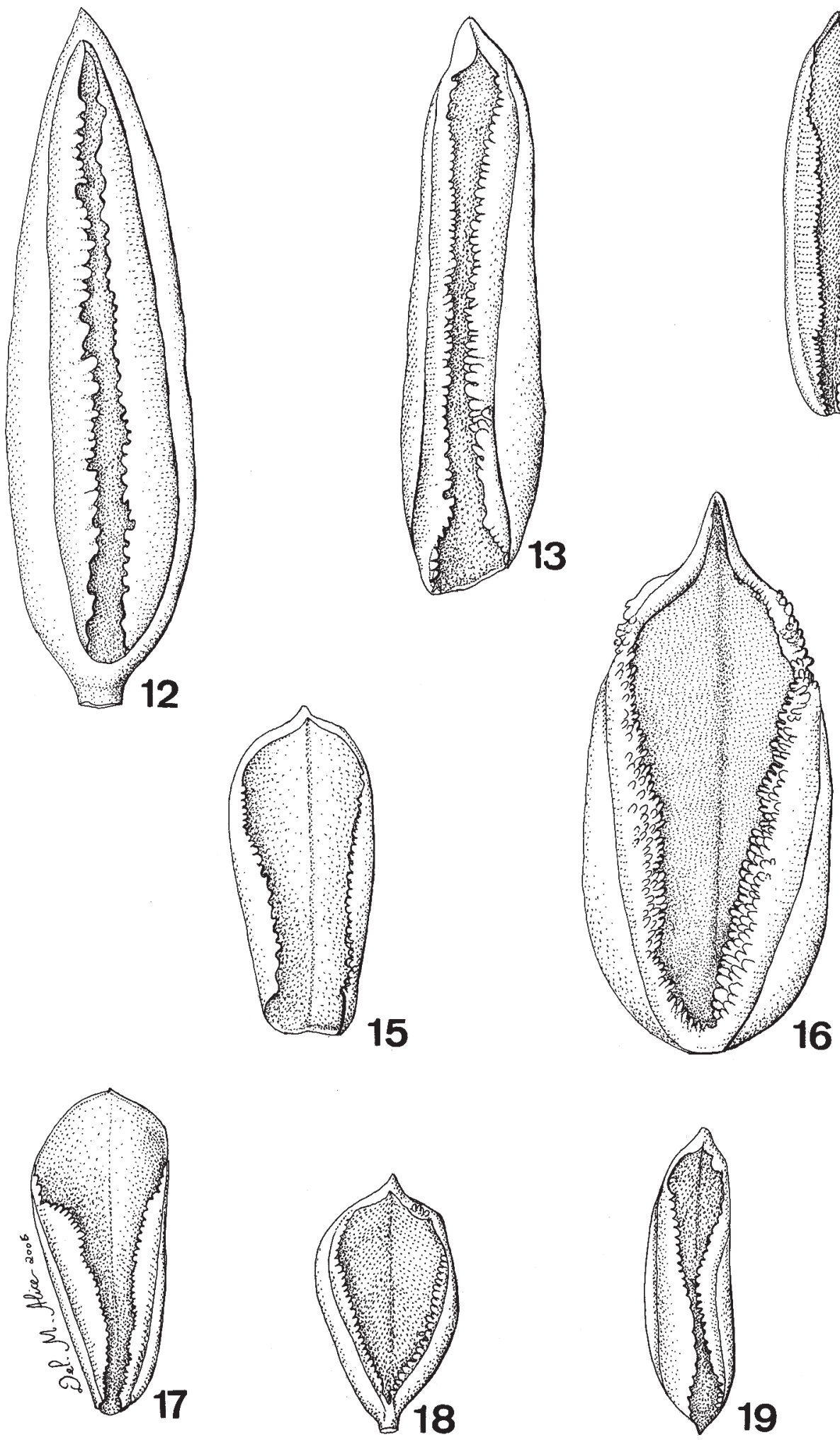

Figuras 12-19. Valvas de cápsulas de Schultesia mostrando a projeção das placentas. 12. S. crenuliflora (Harley 15679). 13. S. heterophylla (Pinheiro Sobrinho s/n BHCB). 14. S. australis (Camargo 66). 15. S. gracilis (Brade \& Barbosa 17687). 16. S. brachyptera (Ducke 10643). 17. S. guianensis var. guianensis (Cavalo et al. 891). 18. S. guianensis var. latifolia (Guimarães \& Miguel 1658). 19. S. doniana (Rocha 370). (Escala: $12-19=5 \mathrm{~mm})$. 

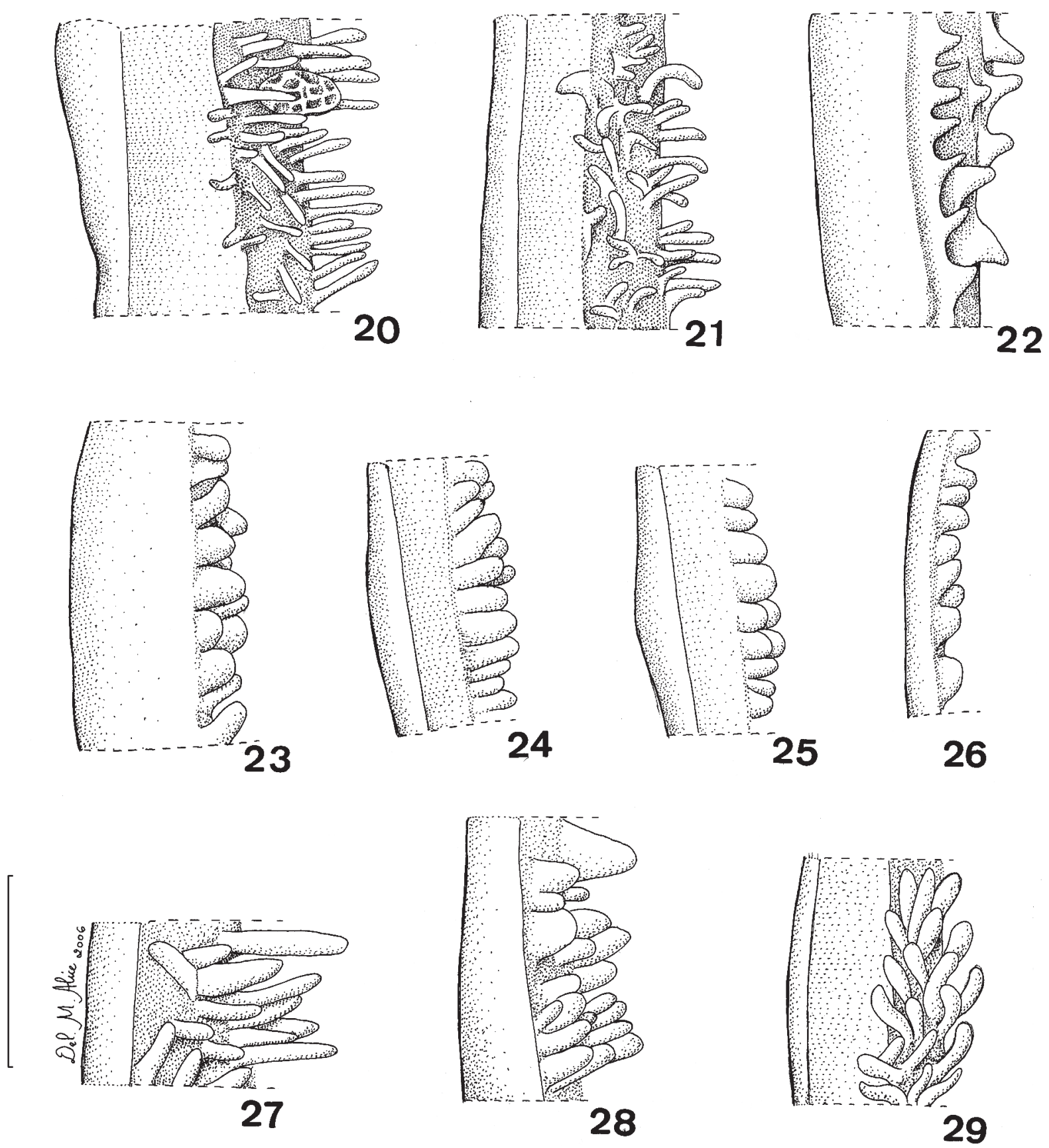

Figuras 20-29: Valvas de Schultesia mostrando os funículos em visão lateral. 20. S. brachyptera (Ducke 10643). 21. S. guianensis var. latifolia (Guimarães \& Miguel 1658). 22. S. doniana (Rocha 370). 23. S. aptera var. aptera (Pires et al. 9158). 24. S. benthamiana (Luetzelburg 1489). 25. S. minensis (Irwin et al. 27561). 26. S. subcrenata (Spruce 1028). 27. S. bahiensis (Guedes 1119). 28. S. crenuliflora (Harley 15679). 29. S. pachyphylla (Hatschbach \& Kummrow 47936). (Escala: 20-29=1 mm). 

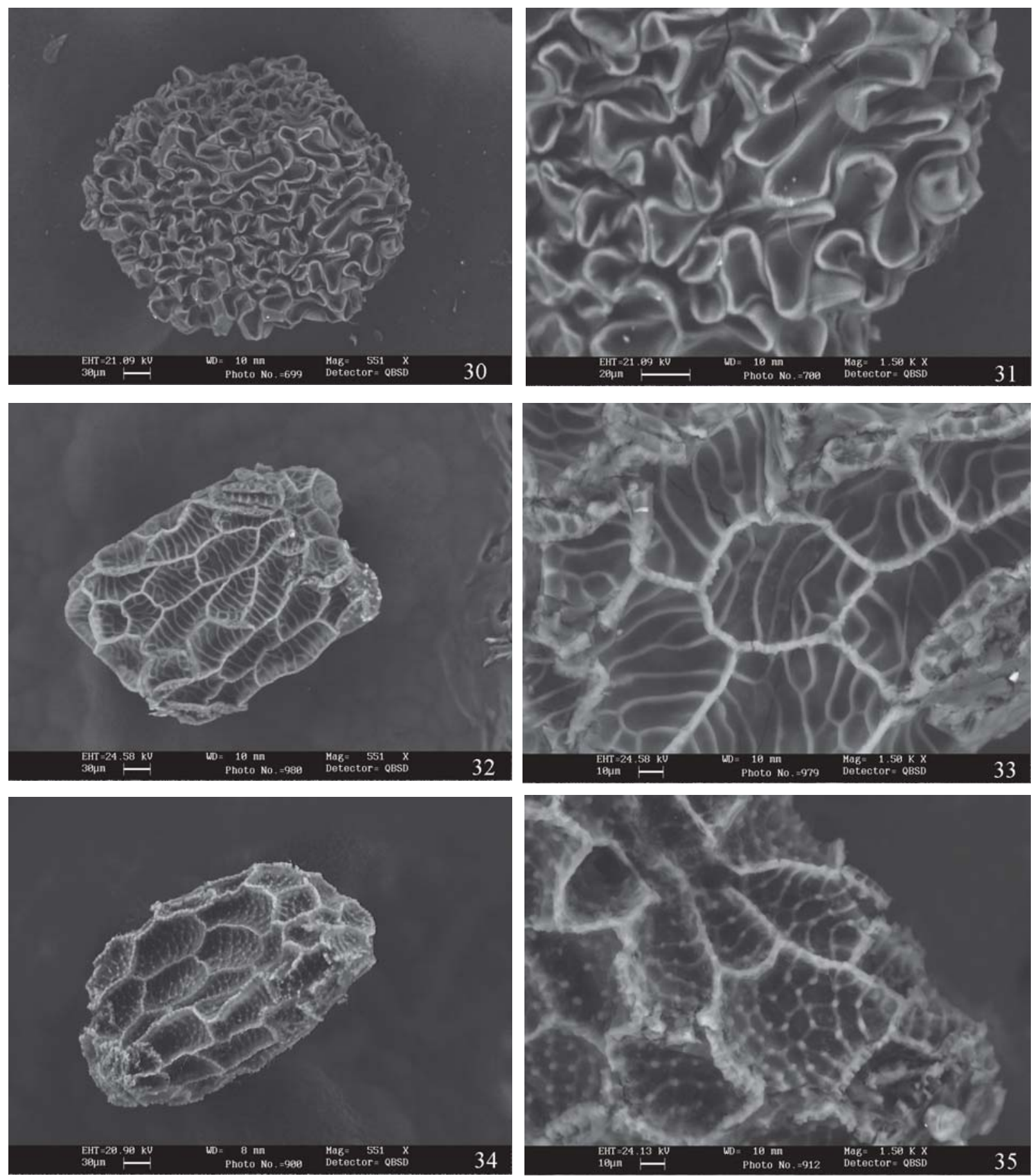

Figuras 30-35. Sementes de Schultesia e Xestaea. 30-31: S. pachyphylla (Martinelli 5475). 30. Vista geral (551X). 31. Detalhe da superfície da testa (1500X). 32-33. X. lisianthoides (Lewis et al. 5206). 32. Vista geral (551X). 33. Detalhe da superfície da testa (1500X). 34-35. S. brachyptera (Ducke 10643). 34. Vista geral (551X). 35. Detalhe da superfície da testa (1500X). 

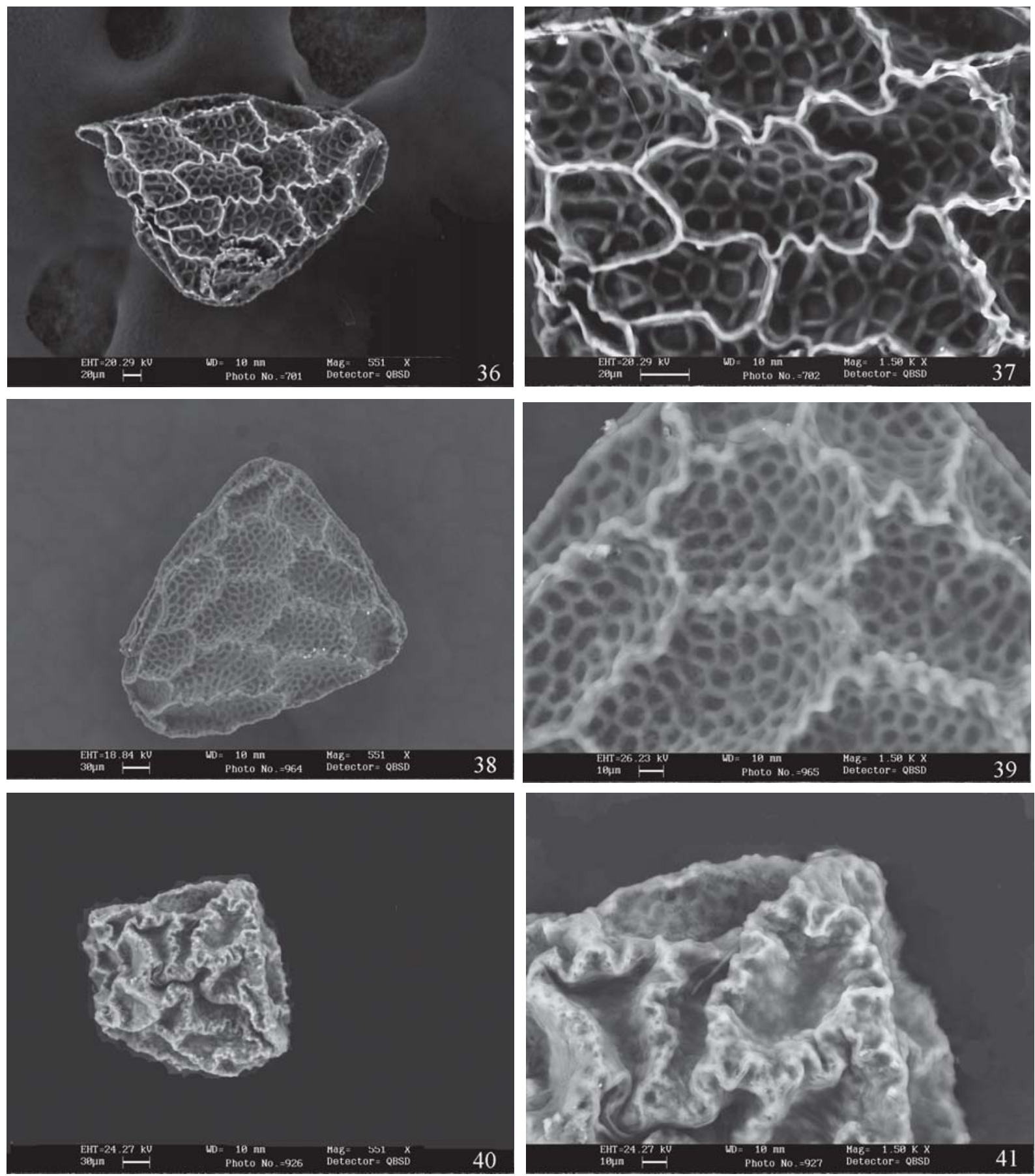

Figuras 36-41. Sementes de Schultesia. 36-37. S. australis (Camargo 66). 36. Vista geral (551X). 37. Detalhe da superfície da testa (1500X). 38-39. S. guianensis var. latifolia (Guimarães RJ-1654). 38. Vista geral (551X). 39. Detalhe da superfície da testa (1500X). 40-41. S. piresiana (Pires 58155). 40. Vista geral (551X). 41. Detalhe da superfície da testa (1500X). 

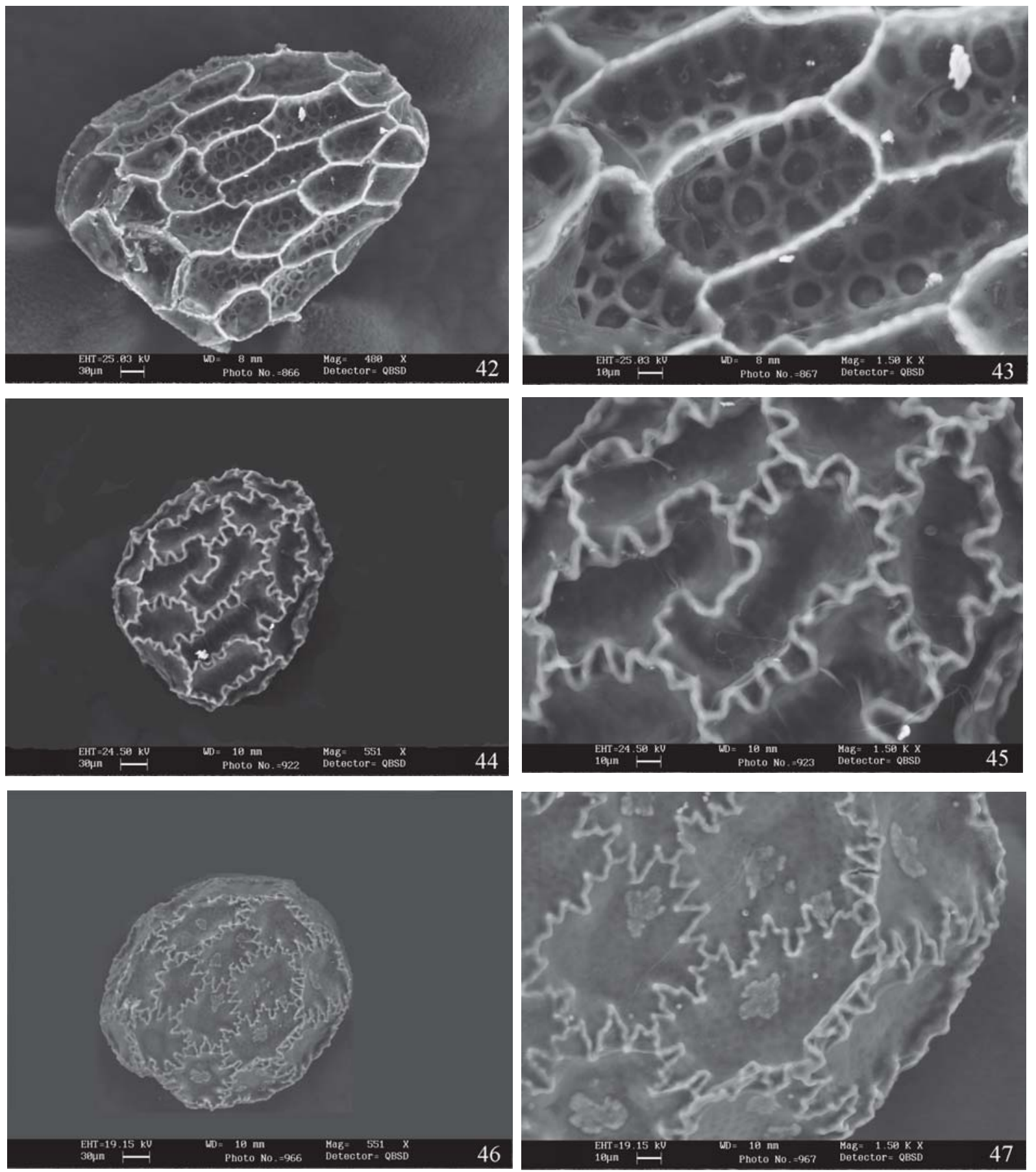

Figuras 42-47. Sementes de Schultesia. 42-43. S. aptera var. aptera (Araújo 905). 42. Vista geral (551X). 43. Detalhe da superfície da testa (1500X). 44-45. S. angustifolia (Netto 47). 44. Vista geral (551X). 45. Detalhe da superfície da testa (1500X). 46-47. S. benthamiana (Luetzelburg 1489). 46. Vista geral (551X). 47. Detalhe da superfície da testa (1500X). 
anticlinais levemente curvas que constituem muri; presença de micropapilas; parede periclinal com padrão estriado de paredes delgadas.

\section{Discussão}

Os frutos de Schultesia e Xestaea são muito semelhantes, caracterizando-se por serem cápsulas septicidas, bivalvares, com ápice agudo que se prolonga em rostro, oriundo do resto do estilete, pericarpo delgado com endocarpo papiráceo a coriáceo, brilhante, com numerosas sementes, que se assemelham aos demais gêneros que compõem a subtribo Coutoubeinae, como Coutoubea (Guimarães \& Klein 1985) e Deianira (Guimarães 1977).

A cápsula de Schultesia varia de 4,8-20 mm compr. e de 1-6,2 mm larg., de consistência papirácea a coriácea, forma elíptica, lanceolada ou oblongolanceolada, base obtusa ou aguda, enquanto a de Xestaea apresenta 9-10 mm compr. e de 2,4-2,7 mm larg., de consistência papirácea, forma lanceolada e base obtusa, observando-se a sobreposição destes caracteres.

Estas cápsulas, quando imaturas, são esverdeadas e à medida que amadurecem, tornam-se castanhas, assim como o cálice persistente e a corola marcescente. Nas espécies que apresentam uma região mediana mais delgada entre as alas ou carenas do cálice, à medida que a cápsula se desenvolve e as sementes atingem a maturidade, ocorre o rompimento desta região, na direção do ápice para a base. As alas e as carenas permanecem aderentes à cápsula. É bastante comum encontrarem-se cápsulas imaturas em plantas ainda com flores, enquanto outras já se encontram abertas, desprovidas de sementes. De um modo geral, a corola, antes da abertura da cápsula, sofre uma torção em seu tubo (Fig. 2). Algumas vezes as cápsulas, já contendo sementes, estão protegidas pela corola ainda não fenecida.

Os frutos são geralmente eretos com os cálices alados ou carenados, persistentes. Algumas vezes sofrem modificação desta posição, devido a uma leve curvatura do pedicelo (S. crenuliflora e S. pachyphylla), o que pode facilitar a dispersão das sementes. Em S. pachyphylla, espécie que não dispõe de região intermediária entre as alas do cálice, não foi observado o dilaceramento do cálice, sendo o fruto mantido em seu interior (Fig. 7).

$\mathrm{Na}$ maioria das espécies a deiscência ocorre do ápice para a base (Fig. 8), às vezes somente até a região mediana, como em $S$. guianensis var. latifolia
(Fig. 4), enquanto em S. pachyphylla a deiscência ocorre da base para o ápice (Figs. 9, 10). O cálice é persistente, tornando-se mais largo após o desenvolvimento do fruto. A corola é marcescente, sofrendo constrição e torção, esfacelando-se freqüientemente pela maturação, restando apenas a nervura central dos lobos da corola, quando as cápsulas estão abertas. Estiletes e estames podem ainda persistir durante o processo de abertura, como em $S$. australis (Fig. 11).

Cada valva está provida, internamente, de duas placentas parietais pouco ou acentuadamente viradas para dentro, que avançam para o espaço central. Quando os carpelos se separam no fruto maduro, as placentas dividem-se ao meio, ficando cada valva com duas metades, permanecendo entre elas um espaço que pode se apresentar retilíneo da base para o ápice (Fig. 12), alargado nas duas extremidades (Fig. 13), mais largo no ápice (Figs. 14-18) ou, ainda, estreitando-se na região mediana (Fig. 19).

As margens placentárias apresentam os funículos longos ou curtos, membranáceos ou espessos, permanecendo após a queda das sementes, tendo sido possível estabelecer grupos para as espécies trabalhadas em ambos os gêneros:

I - Funículos curtos (0,1-0,4 mm) e membranáceos S. angustifolia, S. aptera var. multidentata, S. australis, S. doniana (Fig. 22), S. gracilis, S. guianensis var. latifolia (Fig. 21), S. mexicana, S. piresiana e $S$. pohliana.

II - Funículos curtos (0,1-0,4 mm) e espessos S. aptera var. aptera (Fig. 23), S. benthamiana (Fig. 25), S. minensis (Fig. 24), S. subcrenata (Fig. 26), $S$. sucreana e $X$. lisianthoides.

III - Funículos longos (0,4-0,8 mm) e membranáceos - S. brachyptera (Fig. 20), S. guianensis var. guianensis e $S$. heterophylla.

IV - Funículos longos (0,4-0,8 mm) e espessos S. bahiensis (Fig. 28), S. crenuliflora (Fig. 29) e S. pachyphylla (Fig. 27).

Os funículos, de um modo geral, vêm sendo pouco explorados nas Gentianaceae, não se tendo encontrado referência a estudos deste caráter para os demais gêneros da família. A forma e a consistência dos funículos forneceram elementos que aproximaram os gêneros, uma vez que $X$. lisianthoides não apresentou uma morfologia distinta, neste caráter, de algumas das espécies de Schultesia. Por outro lado, forneceram subsídios para contribuir na identificação das espécies deste gênero. 
Ressalta-se aqui a importância dos estudos através das observações ao MEV que possibilitaram a descrição das sementes com maiores detalhes e o estabelecimento de grupos:

I - Sementes que apresentam superfície da testa ruminada, ruminado-foveada, com relevo formado pela projeção das paredes anticlinais sinuosas; parede periclinal lisa: S. mexicana, S. pachyphylla (Fig. 30, 31) e S. pohliana.

II - Sementes que apresentam superfície da testa não ruminada, foveolada, fóveas irregulares, com relevo formado por paredes anticlinais curvas, retilíneas, sinuosas ou com sinuosidades em "V":

IIa - Paredes periclinais com padrão estriado: Xestaea lisianthoides (Fig. 32, 33).

IIb - Paredes periclinais com padrão reticulado, com células de perfil poligonal de paredes espessas ou delgadas: S. australis (Fig. 36, 37), S. bahiensis, S. brachyptera (Fig. 34, 35), S. crenuliflora, S. gracilis, $S$. guianensis var. guianensis, S. guianensis var. latifolia (Fig. 38, 39), S. heterophylla, S. piresiana (Fig. 40, 41) e S. sucreana.

IIc - Paredes periclinais com padrão reticulado-foveado de paredes espessas: S. aptera var. aptera (Fig. 42, 43), S. aptera var. multidentata, S. doniana e S. minensis.

IId - Paredes periclinais com padrão liso: S. angustifolia (Fig. 44, 45) e S. subcrenata.

IIe - Paredes periclinais com padrão foveolado, paredes anticlinais com sinuosidade acentuada em "V": S. benthamiana (Fig. 46, 47).

Bouman et al. (2002) assinalaram que a testa da maioria das Gentianaceae é reticulada e a estrutura da superfície das sementes é determinada pelo padrão das paredes anticlinais e pelo espessamento das paredes internas periclinais e anticlinais. Acrescentaram que a tribo Chironieae, composta pelas subtribos Canscorinae, Chironiinae e Coutoubeinae, apresenta sementes pequenas de padrão reticulado com células poligonais e paredes das células retilíneas ou onduladas. A parede interna pode apresentar papilas, que podem estar dispostas nos vértices do retículo. Os mesmos autores, ao descreverem a subtribo Coutoubeinae, composta pelos gêneros Coutoubea, Deianira, Symphyllophyton, Schultesia e Xestaea, assinalaram as mesmas características da tribo, acrescentando apenas o caráter da testa reticulada, que se apresenta com células poligonais regulares ou irregulares, e as paredes anticlinais também podendo ser curvas. Entretanto, estes autores trabalharam com apenas algumas das espécies de Schultesia, não tendo sido possível visualizar os padrões ruminado e ruminado-foveado, aqui assinalados.

As sementes de Schultesia, assim como de Xestaea, apresentam um padrão típico da tribo à qual pertencem pela formação de fóveas. No entanto, a diversidade de formas das paredes anticlinais e periclinais permitiu o estabelecimento de grupos. Neste contexto, Xestaea mostra um padrão distinto das espécies de Schultesia, pelo tipo estriado das paredes periclinais, próprio de sua única espécie. Por outro lado, Bouman et al. (2002) afirmaram que as sementes de Xestaea se assemelham a algumas das espécies de Schultesia, sem mencionar os detalhes desta similaridade. Quando analisadas as superfícies das testas, estas autoras observaram que as sementes se apresentam foveoladas, com fóveas irregulares em ambos os gêneros.

Embora Gilg tenha inserido X. lisianthoides em sua seção Xestaea do gênero Schultesia junto a três outras espécies de Schultesia, Guimarães (dados não publicados) observou que ela já se diferenciava deste grupo pelo conectivo prolongado, assim como Guimarães et al. (2003) observaram o pólen de Xestaea com tétrades pequenas e malhas na região de interseção dos grãos consideravelmente menores com relação às demais espécies de Schultesia.

Assim, apesar dos frutos de ambos os gêneros apresentarem-se muito semelhantes, a presente análise das sementes das espécies de Schultesia e Xestaea, aliadas aos estudos dos grãos de pólen (Guimarães et al. 2003), forneceram dados que vieram respaldar os estudos morfológicos dos gêneros Schultesia e Xestaea, corroborando com as pesquisas moleculares que propiciaram o restabelecimento de Xestaea como gênero válido (Struwe et al. 2002).

\section{Agradecimentos}

Ao $\mathrm{CNPq}$, pelas bolsas concedidas; à Petrobrás através do convênio 610.4.025.02.3 / Programa Mata Atlântica/JBRJ; aos curadores de herbários, pelo empréstimo dos materiais; ao Departamento de Patologia Gomes de Farias da Fundação Oswaldo Cruz, em especial ao Dr. Henrique Leonel Lenzi e ao técnico Marcelo Dumas Hahn, pela franquia do laboratório e imagens em Miscrocópio Eletrônico de Varredura. 


\section{Referências bibliográficas}

Aublet, J.B.C.F. 1775. Histoire des Plantes de la Guiane Françoise. v.1. Paris, Pierre-François Didot Jeune, Londres.

Baillon, H.E. 1889. Gentianacées, Apocynacées. Pp. 113-220, Fig. 88-107. In: H.E. Baillon. Histoire des Plantes. L. Hachette et Cie, Paris, Londres, Leipzig, v. 10, n. 1.

Barthlott, W. 1981. Epidermal and seed surface characters of plants: systematic applicability and some evolutionary aspects. Nordic Journal of Botany 1(3): 345-355.

Bentham, G. \& Hooker, J.D. 1876. Gentianeae. Pp. 799-820. In: G. Bentham \& J.D. Hooker. Genera Plantarum. Lovell Reeve e Co., Londres, v. 2, part. 2.

Bouman, F.; Cobb, L.; Devente, N.; Goethals, V.; Maas, P.J.M. $\&$ Smets, E. 2002. The seeds of Gentianaceae. Pp. 498-572. In: L. Struwe \& V.A. Albert (eds.). Gentianaceae: systematics and natural history. Cambridge, Cambridge University Press.

Carvalho, L.d'A.F.; Machado, R.D. \& Bovini, M.G. 1999. Seed coat micromorphology of Brazilian species of Schwenckia. Pp. 23-32. In: M.H. Nee, D.E. Symon, R.N. Lester \& J.P. Jessop (eds.). Solanaceae IV: Advances in Biology and Utilization. Kew, Royal Botanic Gardens.

Cobb, L. \& Maas, P.J.M. 1983. Seed coat micromorphology in Irlbachia (Gentianaceae). Proceedings (Botany) C 86(2): 127-136.

Elias, T.S. \& Robins, A. 1975. Flora of Panama: Gentianaceae. Annals of the Missouri Botanical Garden 62: 61-101.

Endlicher, S.L. 1838. Genera Plantarum secundun ordines naturales disposita. Viena, F. Beck, part. 8.

Gilg, E. 1895. Gentianaceae. Pp. 50-108, Fig. 29-48. In: H.G.A. Engler \& K.A.E Prantl (eds.). Die Natürlichen Pflanzenfamilien... Wilhelm Engelmann, Leipzig, v.4, abt. 2.

Grisebach, A.H.R. 1836. Observationes quaedam de Gentianearum familiae characteribus. Berlim, Nietack.

Grisebach, A.H.R. 1845. Gentianaceae. Pp. 38-141. In: A.L.P.P. de Candolle (ed.). Prodromus systematis naturallis regni vegetabilis... Treuttel et Würtz, Paris, Etrasburgo, Londres, v. 9.

Grisebach, A.H.R. 1849. Gentianeae Juss. In: J.F. Klotzsch. Beiträgen zu einer Flora der Aequinoctial-Gegenden der neuen Welt. Linnaea 22: 32-46.
Grothe, E.H.M. \& Maas, P.J.M. 1984. A scanning electron microscopic study of the seed coat structure of Curtia Chamisso \& Schlechtendahl and Hockinia Gardner (Gentianaceae). Proceedings (Botany) C 87(1): 33-42.

Guimarães, E.F. 1977. Revisão taxonômica do gênero Deianira Chamisso et Schlechtendal (Gentianaceae). Arquivos do Jardim Botânico do Rio de Janeiro 21: 45-123.

Guimarães, E.F. \& Klein, V.L.G. 1985. Revisão taxonômica do gênero Coutoubea Aublet (Gentianaceae). Rodriguésia 37(62): 21-45.

Guimarães, E.F.; Mendonça, C.B.F.; Gonçalves-Esteves, V. \& Pereira, J.F. 2003. Palinotaxonomia de espécies de Schultesia Mart. Gentianaceae Juss. Arquivos do Museu Nacional 61(3): 151-164.

Holmgren, P.K.; Holmgren, N.H. \& Barnett, L.C. 1990. Index Herbariorum: The herbaria of the world. Nova Iorque, New York Botanical Garden.

Lemée, A.M.V. 1934. Dictionnaire descriptif et synonymique des genres de plantes phanérogames. v.5. Paris, Paz Albert Lemée, Brest.

Martius, C.F.P. von. 1826-1827. Nova genera et species plantarum quas in itinere per Brasiliam. v.2. V.Wolf, München

Miquel, F.A.W. 1847. Plantae Fockeanae in Symbolae ad floram surinamensem. Linnaea 19(2): 129-145.

Nilsson, S. 2002. Gentianaceae: a review of palynology. Pp. 377-497. In: L. Struwe \& V.A. Albert (eds.). Gentianaceae: systematics and natural history. Cambridge, Cambridge University Press.

Progel, A. 1865. Gentianaceae. Pp. 197-248, Pl. 55-66. In: C.F.P. von Martius, A.W. Eichler \& I. Urban (eds.). Flora brasiliensis... Munique, Viena, Leipzig, v. 6, part. 1.

Sauget, J.S. \& Liogier, E.E. 1957. Flora de Cuba: Gentianaceae. Contribuciones Ocasionales del Museo de Historia Natural del Colegio de La Salle 4(16): 158-170.

Standley, P.C. \& Williams, L.O. 1969. Flora of Guatemala. Gentianaceae. Fieldiana, Botany 24(8): 302-334.

Stearn, W.T. 1995. Botanical Latin. Portland, Timber Press. Struwe, L.; Kadereit, J.W.; Klackenberg, J.; Nilsson, S.; Thiv, M.; von Hagen, K.B. \& Albert, V.A. 2002. Systematics, character evolution, and biogeography of Gentianaceae, including a new tribal and subtribal classification. Pp. 21-309. In: L. Struwe \& V.A. Albert (eds.). Gentianaceae: systematics and natural history. Cambridge, Cambridge University Press. 